\title{
Perspectives, Tendencies, and Guidelines in Affinity-Based Strategies for the Recovery and Purification of PEGylated Proteins
}

\author{
Luis Alberto Mejía-Manzano, Patricia Vázquez-Villegas, and José González-Valdez \\ Tecnologico de Monterrey, School of Engineering and Science, Av. Eugenio Garza Sada 2501 Sur, Monterrey, NL 64849, Mexico \\ Correspondence should be addressed to José González-Valdez; jose_gonzalez@tec.mx
}

Received 11 July 2019; Accepted 23 December 2019; Published 25 January 2020

Guest Editor: Margarita S. Dominguez

Copyright (c) 2020 Luis Alberto Mejía-Manzano et al. This is an open access article distributed under the Creative Commons Attribution License, which permits unrestricted use, distribution, and reproduction in any medium, provided the original work is properly cited.

\begin{abstract}
In recent years, the effective purification of PEGylated therapeutic proteins from reaction media has received particular attention. Although several techniques have been used, affinity-based strategies have been scarcely explored despite the fact that, after PEGylation, marked changes in the molecular affinity parameters of the modified molecules are observed. With this in mind, future contributions in the bioseparation of these polymer-protein conjugates are expected to exploit affinity in chromatographic and nonchromatographic techniques which will surely derive in the integration of different operations. However, this will only occur as novel ligands which are simultaneously found. As it will be mentioned, these novel ligands may be screened or designed. In both cases, computer-aided tools will support their identification or development. Additionally, ligand discovery by highthroughput screening (HTS) is believed to become a fast, economic, and informative technology that will aid in the mass production of ligands along with genetic engineering and related technologies. Therefore, besides analyzing the state of the art in affinity separation strategies for PEGylated molecules, this review proposes a basic guideline for the selection of adequate ligands to provide information and prospective on the future of affinity operations in solving this particular bioengineering problem.
\end{abstract}

\section{Introduction}

The chemical or physical attachment of polyethylene glycol (PEG) to a molecule or a therapeutic protein is defined as PEGylation [1-3]. Among the benefits that have been associated to this strategy at a general therapeutic level are the increase in protein solubility, size, and thermal and mechanical stability [4], which confer proteolysis resistance and a reduction in renal clearance, immunogenicity, and toxicity [5]. In 2017, the global market of PEGylated therapeutic proteins was valued at US\$10,388 million with an estimated compound annual growth rate (GAGR) of $6.9 \%$ from 2018 to 2025 [6]. To date, there are more than 12 FDA-cleared PEGmodified drugs and about 30 more in research and/or clinical trials [7].

The PEG used in PEGylation can be linear or branched with diverse sizes, depending on the size of the biomolecule to be modified [7]. Polymer molecular weights of 40 to $60 \mathrm{kDa}$ are preferred [2]. To do so, $\mathrm{PEG}$ is functionalized with different chemical groups (i.e., amino, hydroxyl, imidazole, histidine, thiol, disulfide, carboxylic, hydrophobic, or electrostatic residues) [8]. Depending on the kind of reaction used, PEGylation can be classified into noncovalent or covalent, and the last one is subdivided into random or site-specific [9]. Noncovalent PEGylation exploits hydrophobic or ionic interactions to form coordination complexes between the protein and the polymer [9]; however, these are scarcely used because the PEG coating can be easily removed [10]. On the contrary, covalent techniques involve the formation of fixed chemical bonds which can be site-specific in some cases. PEGcarboxylates, PEG-carbonates, or PEG activated with $\mathrm{N}$-hydroxysuccinimide are examples of agents that lead to random or unspecific PEGylations [9]. Among the strategy examples to obtain site-specific conjugation, we can find N-terminal thiol bridging or enzymatic PEGylations [9]. Although a site-specific modification is always preferred, it can be expensive, it is not always feasible, or it may require 
a high expertise and development time [11]. Furthermore, if the molecule presents several of these target-specific sites, the reaction tends to produce PEGylated species that vary in modification degree (number of attached chains) and positional isomerism [11] as it occurs with random PEGylation. In this context, the mono-PEGylated conjugate is usually the most adequate isomer regarding the desired properties and biological activity for its therapeutic function. Thus, the recovery and purification of the right conjugate with the desired yield and purity result in a sophisticated and resource-consuming procedure.

Current separation methods to purify the monoPEGylated conjugates can be classified into two main groups: chromatographic and nonchromatographic techniques [12]. Within the nonchromatographic techniques, ultrafiltration has been applied in the recovery of PEGylated ovalbumin, bovine serum albumin, $\alpha$-lactalbumin, and ribonuclease A (RNase A) [13], with the disadvantages of obtaining low recoveries and the high cost of the membranes. On their part, aqueous two-phase systems (ATPS) have demonstrated to be a promising technique in the fractionation of PEGylated proteins in PEG-phosphate systems [14, 15], but until now, the operation has not been carried out at pilot or industrial scales. Polyacrylamide gel electrophoresis (PAGE) is used mainly for the characterization or analysis of the modified molecules, requiring the use of an additional step to remove the dyes used in the staining of the proteins [12].

On the contrary, chromatographic techniques are still the preferred method for PEGylated conjugate purification. Size exclusion chromatography (SEC) has been effective to remove low molecular weight impurities and nonreacted proteins, nevertheless SEC has been unable to distinguish between conjugates and positional isomers causing poor resolution, high buffer consumption, large sample dilution, and long processing times [16, 17]. Ion exchange chromatography (IEX) takes advantage of protein charge modification due to PEG shielding, that is to say, the covering of the protein surface and the loss of a positive charge for each linked PEG chain [18]. However, the negative aspects of this methodology are low dynamic binding capacity of proteins with long PEG chains [19], short support lifetimes, and low column loads. On its part, reverse phase chromatography (RPC) has been applied for the analysis of PEG-conjugates in HPLC systems more than in preparative levels because the high temperatures and the use of organic solvents in the mobile phase cause protein denaturation [16]. Hydrophobic interaction chromatography (HIC) has been successfully implemented for the recovery of modified proteins with different degrees of PEGylation, but in this method, free PEG is also linked to the stationary phase, and there is a lack of predictive understanding of molecule retention which makes HIC not suitable for its use at large scales [20].

One of the discussed aspects of protein PEGylation is the change in the affinity parameters of the protein after its reaction. In this sense, affinity-based separations might be an effective and attractive option in the purification of protein-polymer conjugates considering the high selectivity that characterizes the interactions involved. This review analyzes different studies about the effects of PEGylation on the affinity of the modified molecules and presents current reports on affinity-based purification strategies for these conjugates. Distinctive tools in the screening/design and production of novel ligands are also referred. Future trends and challenges in the bioseparations of PEGylated proteins by affinity methods are elucidated, and a guide procedure to select the adequate ligand and operation for the purification of a PEG-modified protein is proposed.

\section{Effects of PEGylation on Protein Affinity}

As it has been mentioned, PEGylation has been used as a strategy to reduce the immunogenicity of some therapeutic biomolecules, proteins, or antibodies and to diminish dose frequency in patients [4]. In general terms, the affinity of PEGylated proteins towards biological agents is affected and is expected to change depending on the extent of the PEGylation procedure, [21] but there is still a lack of understanding on how this occurs. In this aspect, some reports have registered a decrement on the affinity of the PEGylated enzyme towards its biological counterpart. For instance, native ribonuclease $\mathrm{A}$ (RNase $\mathrm{A}$ ) had a dissociation constant $\left(k_{\mathrm{d}}\right)$ of $7.6 \times 10^{-8} \mathrm{M}$, while modified RNase A with 4 and 9 PEG molecules had $k_{\mathrm{d}}$ of $1.3 \times 10^{-7} \mathrm{M}$ and $1.2 \times 10^{-6} \mathrm{M}$, respectively [22]. Chapman [4] concluded from his research with antibodies that affinity is reduced in random PEGylation more severely employing amine-reactive chemistries and in the cases when two or more attached PEG molecules per antibody molecule are found. He also reports a $50 \%$ inhibition of the Fc (fragment crystallizable) receptor binding in the antibody when $25 \%$ of the available amines were modified by random PEGylation. Furthermore, Fc activity was more affected than the antigenic binding activity. This report describes, as well, that, in site-specific PEGylation of complete antibodies or antibody fragments, the affinity binding is retained. However, it also suggests that binding loss may be caused by ionic interference rather than affinity interference [4]. In summary, Chapman states that the changes in affinity vary in every case depending on the protein size, surface density, length of the PEG chains, and of course the PEGylation strategy used [4]. All these factors have an accumulative effect, and the closer the modification site is to the binding or active site, the most severe is the effect in its affinity. In those cases in which affinity loss occurs during the PEGylation of some drugs, the negative effect may be compensated through the application of the multivalence concept (the binding of more than one biomolecule to a macroligand) as it has been observed in the conjugation of PEGylated ligands to nanoparticles [23].

\section{Current Advances in the Purification of PEGylated Proteins through Affinity Procedures}

Affinity-based bioseparations are techniques that exploit a biological recognition phenomenon, which is reversible and 
specific, to achieve the separation of one or several of the desired biomolecules from their contaminants [24]. Such procedures require operations such as chromatography, precipitation, membrane-based purifications, and two-phase extractions. [24] These can also be grouped as affinity nonchromatographic and chromatographic techniques. The essential steps in a protein affinity-based bioseparation (regardless of the operation type) are (1) the capture of the protein with the ligand (which can be free or linked to a particular matrix), (2) washing or separation of the contaminants of the mixture, and (3) elution or recovery of the target protein [25].

Even when affinity bioseparations have been highly demanded for the isolation of pharmaceutical proteins, their use in polymer-protein conjugates recovery has been poorly studied. The change in affinity properties has been mainly addressed in chromatographic techniques mostly because chromatography will continue to be the preferred method for biopharmaceutical purification because of its high-resolution capabilities [26].

Affinity chromatography (AC) is a selective and powerful purification operation which is based on a highly specific biological interaction between a target and a ligand [27-30]. The advantages attributed to AC are high selectivity and specificity, high sample concentration, high level of purification (greater than 1,000-fold), scalability [31], conservation of biological activity using gentle operations, and time saving. Until now, the applications of affinity chromatography for the purification of PEGylated proteins after a PEGylation reaction are scarce. There are only two works dealing to some extent with affinity chromatography of PEG-modified proteins. In one of these works, the purification of $20 \mathrm{kDa}$ mono-PEGylated lysozyme with heparin affinity chromatography was optimized through an experimental design [32], and the elution curves for the operation were later simulated [33]. The other studies deal with the PEGylation of ligands in AC supports or resins, with the aim of improving their stability using as model concanavalin and protein A [34, 35].

Regarding possible ligands for PEGylated proteins, the discovery of induced immunogenicity in patients and animals administered with PEG-protein conjugates was the antecedent for the identification and isolation of anti-PEG antibodies [36]. The existing anti-PEG antibodies are of IgG and IgM isotypes, and several of them are available commercially (Table 1). However, much has been questioned regarding their specificity [37], but in current studies, interesting conclusions have been obtained. One of them is that none of the monoclonal or polyclonal anti-PEG antibodies are totally methoxy or backbone-specific, so these show relative specificities. For example, the anti-PEG antibodies inducted by HO-PEG-proteins target the backbone but not the hydroxyl end-group [38, 39]. In those antibodies raised against metoxi-PEG (mPEG)-proteins, the affinity depends on the hydrophobicity of their end-groups and the backbone lengths of the polymers, so anti-mPEGs presented a few hundreds of times more affinity for $10 \mathrm{kDa}$ mPEG than for mTEG (tri(ethylene glycol) monomethyl ether) [38]. The reported applications using anti-PEG antibodies enclose diagnosis, analysis, and quantification of both PEG and PEGylated proteins. Only in one work, the anti-PEG antibody PEG B-47 (rabbit IgG1 monoclonal antibody) was used as part of an immunoaffinity purification, and the antibody was bound to streptavidin-coated magnetic beads for the capture of the MK-2662 peptide PEGylated with $40 \mathrm{kDa}$ branched PEG at C-terminus [40]. The captured peptide was digested and injected in 2D-HPLC followed by a triplequadrupole mass spectrometer detector [40]. However, in this work, the peptide is destroyed making the application fundamentally analytic, which is not recommended if peptide recovery is wanted. In the same way, our research group is attempting to use anti-PEG antibodies as selective ligands in PEG-protein downstream processes but from a preparative perspective.

Approaches on using affinity chromatography for carrying out PEGylation reactions with better effectiveness (denominated affinity on-column PEGylation or solidphase PEGylation) have also been performed. This methodology consists on integrating the reaction and purification operations in a single step with the goal of doing a more site-specific PEGylation and protecting the active or binding site in enzymes or proteins from PEG alteration [41]. The protein is adsorbed onto the affinity matrix, and then PEGylation is performed during protein retention [42]. Table 2 shows examples in which solidphase PEGylation with affinity chromatography has been applied to important therapeutic proteins. On-column PEGylation ensures the catalytic activity after the PEGmodification, especially in proteins with modifiable amino acids in the binding site as it happens with the presence of lysines, which can be attacked during N-terminal PEGylation [8]. As consequence, protein biological activity is more conserved than in random PEGylation. Table 2 displays, for the most part, relative bioactivities greater than $50 \%$, whereas in unplanned PEG conjugations, the achieved bioactivity is only $40 \%$ or even null. In general, solid-phase PEGylation has improved yields for the monoPEGylated protein in comparison to liquid-phase PEGylation [44, 46]. Furthermore, on-column PEGylation represents an attractive integration of operations obtaining a desirable product with less downstream steps [47] in less time and with guaranteed biological activity. Nevertheless, this is not always true since in some cases, affinity changes between the nonmodified and the mono-PEGylated product are not enough to resolve both proteins in the elution step of the AC $[44,45]$. Also, when multiple conjugates are formed due to the high number of modifiable amino acids in the protein surface [42], a second purification chromatography (SEC or IEX) could be mandatory.

In general, the affinity property for the isolation of PEGylated proteins has only been exploited with chromatography in a small number of works. The integration of PEGylation and chromatography is a common approach with the aim of improving PEGylation yields and reducing isomer appearance. However, the use and study of preparative affinity chromatography needs to be encouraged. 
TABLE 1: Commercial anti-PEG antibodies and recommended applications.

\begin{tabular}{|c|c|c|c|c|c|c|}
\hline Antibody & Isotype & Class & Source & Company & Specificity & Suggested applications \\
\hline B-47 & G & Monoclonal & Rabbit & $\operatorname{RabMAb}^{\circledR}$ & Metoxi-PEG of conjugates & ELISA, WB, IHC \\
\hline PEG-2-128 & M & Monoclonal & Rabbit & $\mathrm{RabMAb}^{\circledR}$ & PEG backbone & ELISA, WB \\
\hline RM105 & G & Monoclonal & Rabbit & $\mathrm{RabMAb}^{\circledR}$ & Metoxi-PEG & $\begin{array}{l}\text { ICC, WB, ELISA, IHC, flow Cyt, } \\
\text { IP }\end{array}$ \\
\hline $5 \mathrm{D} 6-3$ & G1 & Monoclonal & Mouse & $\mathrm{RabMAb}^{\circledR}$ & PEG backbone & ELISA, WB \\
\hline PA5-32247 & G & Polyclonal & Rabbit & $\begin{array}{l}\text { Thermo Fisher } \\
\text { Scientific }{ }^{\circledR}\end{array}$ & PEG & WB \\
\hline 09F02 & G3 & Monoclonal & Mouse & Lifespan BioSciences ${ }^{\circledR}$ & PEG & ELISA \\
\hline $\begin{array}{l}\mathrm{THE}^{\mathrm{TM}} \text { PEG } \\
\text { antibody }\end{array}$ & M & Monoclonal & Mouse & Lifespan BioSciences ${ }^{\circledR}$ & $\begin{array}{l}\text { PEG backbone and } \\
\text { conjugates }\end{array}$ & ELISA, IHC, IP, WB \\
\hline E11 & G1 & Monoclonal & Mouse & Lifespan BioSciences ${ }^{\circledR}$ & PEG backbone & ELISA \\
\hline 3.3 & G1 & Monoclonal & Mouse & Lifespan BioSciences ${ }^{\circledR}$ & $\begin{array}{l}\text { PEG backbone and } \\
\text { conjugates }\end{array}$ & ELISA, WB, flow Cyt \\
\hline 6.3 & G1 & Monoclonal & Mouse & Lifespan BioSciences ${ }^{\circledR}$ & PEG backbone & ELISA, WB, flow Cyt \\
\hline $15-2 b$ & G2 & Monoclonal & Mouse & Lifespan BioSciences ${ }^{\circledR}$ & Metoxi-PEG & ELISA, WB, flow Cyt \\
\hline r33G & G3 & Monoclonal & Rat & Lifespan BioSciences ${ }^{\circledR}$ & PEG backbone & ELISA \\
\hline AGP3 & $\mathrm{M}$ & Monoclonal & Mouse & Lifespan BioSciences ${ }^{\circledR}$ & PEG backbone & ELISA, WB, flow Cyt, IHC \\
\hline rAGP6 & M & Monoclonal & Mouse & Lifespan BioSciences ${ }^{\circledR}$ & PEG backbone & ELISA, WB \\
\hline PEGPAB-01 & G & Polyclonal & Rabbit & Lifespan BioSciences ${ }^{\circledR}$ & PEG & WB \\
\hline
\end{tabular}

ELISA: enzyme-linked immunosorbent assay, WB: western blot, IHC: immunohistochemistry, ICC: immunocytochemistry, and IP: immunoprecipitation.

TABLE 2: Affinity solid-phase PEGylation of some important proteins.

\begin{tabular}{|c|c|c|c|c|c|c|}
\hline Protein & Affinity support & Used PEG reagent & $\begin{array}{l}\text { Mono- } \\
\text { PEGylated } \\
\text { yield }(\%)\end{array}$ & $\begin{array}{l}\text { Formation of multi- } \\
\text { PEGylated }\end{array}$ & $\begin{array}{c}\text { Relative } \\
\text { bioactivity }^{\mathrm{a}} \\
(\%)\end{array}$ & Reference \\
\hline L-Asparaginase & $\begin{array}{l}\text { L-Asparagine } \\
\text { Sepharose CL- } \\
4 \mathrm{~B}\end{array}$ & $\begin{array}{l}5 \mathrm{kDa} \text { cyanuric } \\
\text { chloride } \mathrm{mPEG}\end{array}$ & - & No & $50.2^{\mathrm{b}}$ & {$[43]$} \\
\hline Catalase & $\begin{array}{l}\text { Procion Red } \\
\text { Sepharose CL- } \\
\text { 4B }\end{array}$ & $\begin{array}{l}6 \mathrm{kDa} \text { cyanuric } \\
\text { chloride } \mathrm{mPEG}\end{array}$ & - & No & $46.5^{\mathrm{c}}$ & {$[43]$} \\
\hline $\begin{array}{l}\text { Recombinant fibroblast } \\
\text { growth factor } 2 \text { (FGF-2) }\end{array}$ & $\begin{array}{l}\text { Heparin } \\
\text { Sepharose }\end{array}$ & $\begin{array}{l}20 \mathrm{kDa} \text { mPEG } \\
\text { butyraldehyde }\end{array}$ & 58.3 & No & $105.4^{\mathrm{d}}$ & {$[44]$} \\
\hline $\begin{array}{l}\text { Recombinant human } \\
\text { keratynocite growth factor } \\
1 \text { (RhKGF-1) }\end{array}$ & $\begin{array}{l}\text { Heparin } \\
\text { Sepharose }\end{array}$ & $\begin{array}{l}20 \mathrm{kDa} \text { mPEG } \\
\text { butyraldehyde }\end{array}$ & 40 & No & $89.6^{\mathrm{d}}$ & {$[45]$} \\
\hline $\begin{array}{l}\text { His-tagged recombinant } \\
\text { staphylokinase (trSak) }\end{array}$ & $\begin{array}{c}\mathrm{Ni}^{2+}-\mathrm{IDA} \\
\text { Sepharose 4FF }\end{array}$ & $\begin{array}{c}\text { Succinimidyl } \\
\text { carbonate mPEG }(5,10, \\
20 \mathrm{kDa})\end{array}$ & $\begin{aligned} & 5 \mathrm{kDa}>40 \\
& 10 \mathrm{kDa}>30 \\
& 20 \mathrm{kDa}>28 \\
&\end{aligned}$ & $\begin{array}{l}\text { Yes (di-PEG) in } \\
\text { PEGylation with } 5 \text { and } \\
10 \mathrm{kDa}\end{array}$ & $\begin{array}{l}5 \mathrm{kDa}>83^{\mathrm{e}} \\
10 \mathrm{kDa}>81 \\
20 \mathrm{kDa}>75\end{array}$ & {$[42]$} \\
\hline
\end{tabular}

${ }^{\mathrm{a}}$ Kept bioactivity after PEGylation respect to bioactivity of the unmodified protein. Bioactivity was measured in a different way for each protein. ${ }^{\mathrm{b}} \mathrm{Measured}$ absorbance at $500 \mathrm{~nm}$ of ammonia with Nessler's method. 'Spectrophotometrical measure of the decrease in absorbance of $\mathrm{H}_{2} \mathrm{O}_{2}$ at $240 \mathrm{~nm}$. ${ }^{\mathrm{d}} \mathrm{Mitogenic}$ activity measured by NIH3T3 cell proliferation assay. ${ }^{\mathrm{e}}$ In vitro bioactivity was measured as the diameter of the halo around the well in Petri dishes with the fibrinogen powder.

\section{Future Trends and Perspectives in the Affinity Purification of PEGylated Proteins}

Future advances in the affinity purification of PEGylated proteins will be highlighted in two main pathways. One being the search or generation of novel ligands for PEGmodified proteins and the second one centered in the development of nonchromatographic affinity strategies. Regarding the first aspect, there are still very few known ligands for PEGylated proteins (basically heparin and anti-PEG or anti-PEGylated protein antibodies). This leads to promote the search or design of novel ligands at high production levels. The strategies to look for novel ligands will be addressed in the next section of this review.

Regarding the need of nonchromatographic affinity techniques, the unit operations considered until now are aqueous two-phase systems (ATPS), affinity-membrane separations, affinity precipitation, and magnetic strategies (Figure 1). ATPS are a promising liquid-liquid recovery operation for their simplicity, economy, having low energy consumption, high scalability potential, and preservation of the biological activity [48-50]. Affinity ATPS have been used to separate a great variety of proteins, molecules, and cells $[51,52]$, but there is an opportunity 


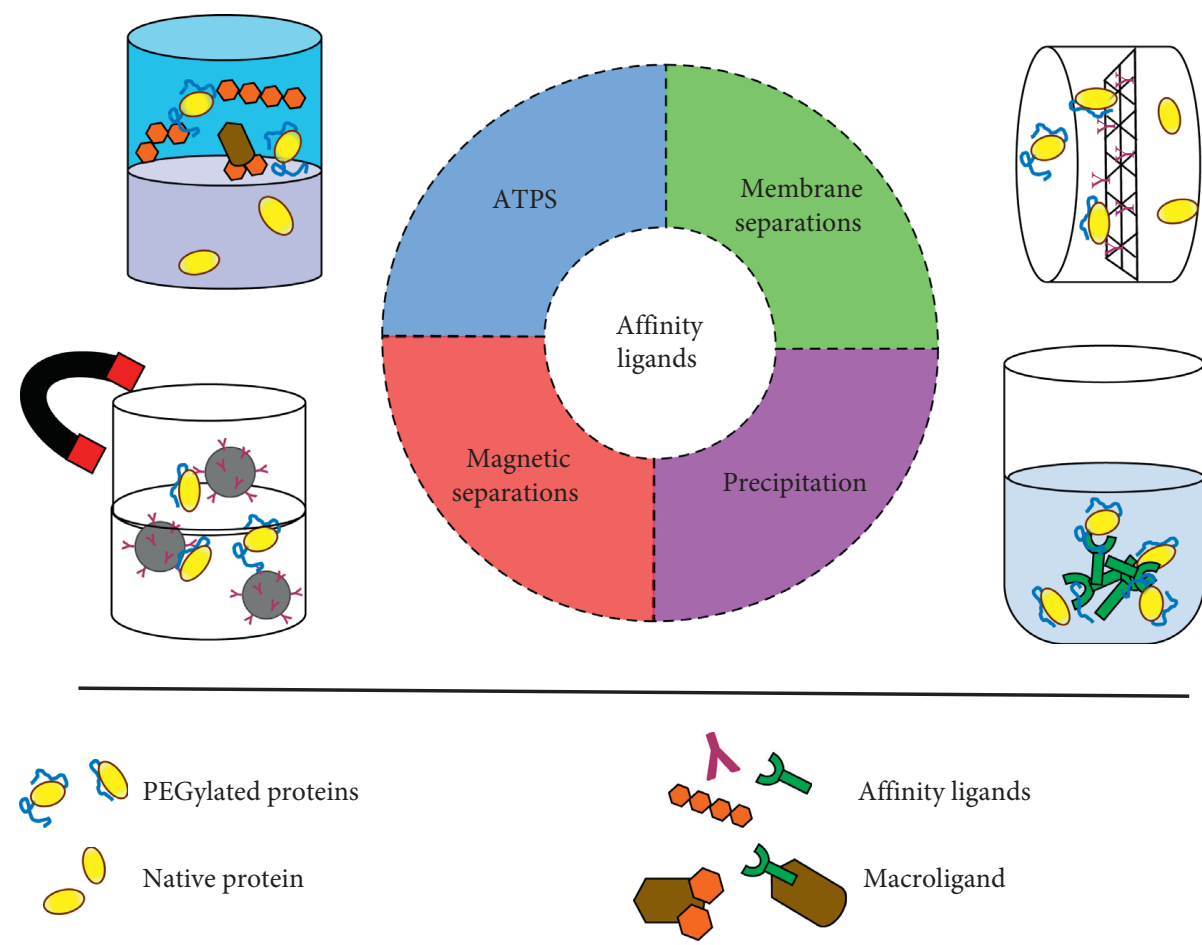

Figure 1: Potential nonchromatographic affinity-based strategies to be highlighted in the future recovery and purification of PEG-modified proteins.

area for PEG-modified proteins. In affinity-ATPS, the preferred systems have been PEG-dextran systems using antibodies, enzymes, or binding molecules as affinity elements. Affinity ATPS may be constructed for the purification of PEGylated proteins using the already known ligands for them.

It should be mentioned that by themselves, some individual PEGylated proteins (mono-PEGylated RNase A and $\alpha$-lactalbumin) have showed preference for the top-phase (or PEG-rich phase) in PEG-phosphate systems $[15,53]$, but the use of affinity ligands may increase the recovery of these proteins in the PEG-rich phase. Incorporation of antiPEGylated protein antibodies as ligands of PEG-modified proteins could favor the partitioning of these conjugates toward a determined phase. Reports about partitioning of antibodies in PEG-phosphate systems have shown that the polymers with low molecular weights favor the antibody partitioning in the PEG-rich phase unlike of systems using large PEGs in which antibodies are found in the salt-rich phase $\left(K_{\mathrm{P}}<1\right)$. However, in this last case, the use of neutral salts like $\mathrm{NaCl}$ modifies the recovery of antibodies to the upper phase minimizing the polymer exclusion effects [54]. In PEG-dextran systems, antibodies partition to the bottom dextran-rich phase, but the use of some ligands for the antibody or modified PEGs [55] has enabled the partition of these antibodies to the top PEG-rich phase. With this in mind, further studies should be performed on the partition of those antibodies intended to be used for the primary recovery of PEGylated proteins to identify those systems in which these conjugates could be recovered. As it has been seen with most antibody partitioning studies, similar results could be expected leading to a good application for these purposes.

Affinity filtration, on its part, retains a protein that normally would pass through the membrane pores with the use of an affinity ligand. Its advantage is the specificity combined with the speed and the high-volume processing capacity of the membranes [56]. During the last few decades, affinity membranes have been coupled with chromatographic equipment giving place to membrane affinity chromatography (MAC) and to monolithic supports. MAC offers less risk of fouling or clogging and faster separations at semipreparative level [57].

Another alternative for the purification of PEGylated proteins is affinity precipitation. This technique can be defined as the specific and scalable solid-liquid separation of an insoluble substance (precipitate) induced by chemical or physical changes [58]. Temperature, $\mathrm{pH}$, and salt concentration are factors involved in precipitate formation. For PEG-proteins, three different formats of affinity precipitation can be proposed: simple one-ligand, mixed-ligand and macroligand, or indirect precipitation. One and mixed-ligand formats can be categorized as primary or direct precipitation [58], where a unique and selective ligand (e.g., anti-PEGylated protein antibody) is used for capturing PEGylated proteins (Figure 2(a)). Mixed-ligand formats require a mixture of two ligands (e.g., anti-PEGylated protein and native protein antibodies) to fractionate the PEGylation reaction with different sedimentary velocities. Here, the separation is characterized basically for the ability of a first ligand to recognize only PEGylated proteins and a second ligand that recognizes the native unreacted protein 
(a)

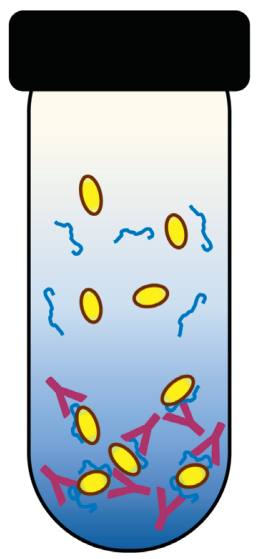

(b)

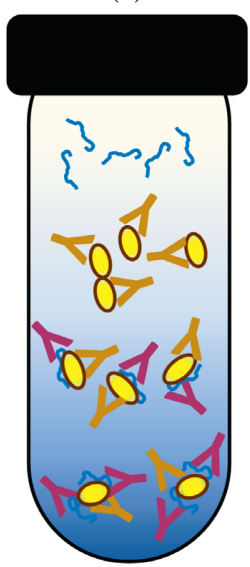

(c)

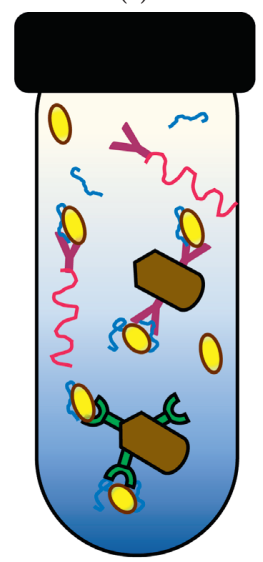

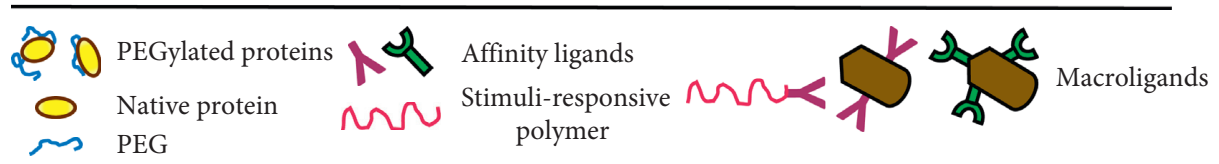

FIgURE 2: Proposed designs for the affinity precipitation of PEGylated proteins.

(Figure 2(b)). To be successful, the fractionation according with the size of the complexes could be achieved through gradual precipitation. In the third format, macroligands, which are bifunctional agents formed by a first molecule and the ligand, in which the first molecule can be a biomolecule (e.g., protein A, tags, and carrier proteins) binding one or several ligands (Figure 2(c)); stimuli-responsive polymers belong to this group and are well represented by acrylamide copolymers [59]. Application of stimuli-responsive polymers would have to be evaluated in the case of PEG-proteins due to the interactions between the polymers and the protein.

Magnetic affinity separations are characterized as simple, fast, gentle, versatile, scalable, and automated processes $[60,61]$. For proteins, there are two modes of affinity magnetic separations: direct and indirect. In the direct method, the ligand must be coupled to the magnetic particle to capture the target protein; in the indirect method, the ligand and magnetic particles are added separately, leaving the ligand the function to interfere in the union of the target and the magnetic particle [60]. Nowadays, magnetic particles and separators are available commercially; the particles are sold with functional groups, in activated forms or with the embedded ligands, which make their procurement and use relatively easy. The application of the presented affinity nonchromatographic separation for PEGylated proteins will be conditioned by overcoming some hurdles such as abundance, recycling, and stability of the ligand in the purification media, so as the use of an efficient methodology for conjugate tracking and characterization.

The use of nanoparticles may be interesting in affinitybased separations of PEGylated proteins because of the multivalency and high avidity that nanoparticles present [23]. Through this route, PEGylated angiotensin II receptor type 1 has been bound to multivalent nanoparticle counterbalancing the affinity loss (up to 600-fold affinity decrease) caused by
PEG-modification [62]. Ligands for PEG-proteins such as anti-PEGylated protein antibodies or those developed in the future might be immobilized firstly on nanoparticles (Figure 3) and in this way, improve the affinity capacity of the nonchromatographic technique and affinity loss and recoverability of the ligand.

A general trend in bioseparations is the design of simple one-stage operations commonly called process integration [63]. Many of the described nonchromatographic options can be combined with each other or with chromatography (as in $\mathrm{MAC}$ ) in a unique purification stage and increase the efficiency of the individual operations until reaching the observed performance of chromatographic techniques. This integration is not restricted only to separation stages but also to production as it is visualized in "solid-phase PEGylation." Following the trend of process integration, affinity magnetic ATPS or so-called magnetic extraction phases (MEP) are not far away from being considered for the recovery of PEGylated proteins as well. Works dealing with this alternative for a mixture of lysozyme and ovalbumin have already been assayed [64]. In this work, a cationic magnetic adsorbent and a nonionic surfactant (Triton X-114) are added to the protein mixture. The magnetic adsorbent captured lysozyme, and a biphasic system is later formed heating at $30^{\circ} \mathrm{C}$ and excluding the magnetic particles to the lower surfactant-rich phase. The top-phase is eliminated, and lysozyme was eluted and separated of the magnetic particles increasing temperature again. The purity $(>80 \%)$ and yield $(74 \%)$ of the lysozyme are then comparable to those where only the magnetic cation exchange was performed [64]. In this context, this integral approach results interesting if applied to PEGylated proteins since modified and native proteins may be separated from the reaction media in a first phase elimination to later elute each protein isomer, varying the process conditions. Another appropriate combination might be affinity ATPS and precipitation, in which selective recognition of PEGylated proteins 
(a)
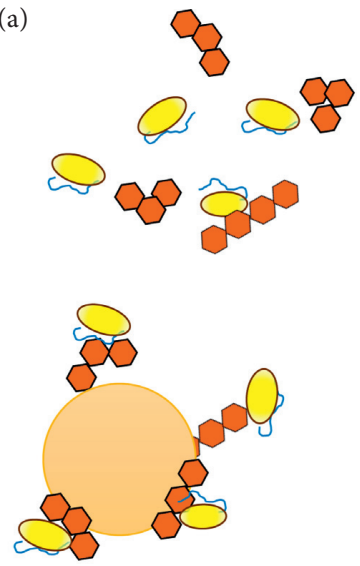

PEGylated proteins
Anti-PEGylated protein antibody (b)
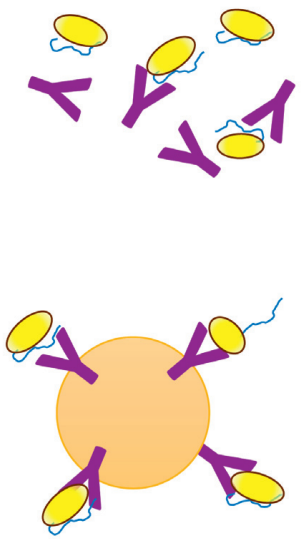

FIgURE 3: Improved affinity by immobilizing PEGylated protein ligands on multivalent nanoparticles.

with a macroligand would be partitioned to the upper phase in a PEG-salt or PEG-dextran system [25] and later performing the separation of this phase to have a precipitation induced by a mild change in the system.

As conclusion, trends point to the development of nonchromatographic affinity techniques and their integration in the recovery of proteins modified with PEG, including the use of multiple ligands or macroligands.

\section{Guidelines in the Selection and Development of Affinity Purification Strategies for PEGylated Proteins}

When a protein affinity purification method is needed and the experience in downstream processing is limited, a common query is how to choose the best strategy to do this. This same doubt is not foreign to PEGylated protein purification. Considering that the ligand and unit operation selections must be based firstly on getting a fast, economic, and practical purification process, one starting point to choose the best strategy is to know if the PEGylation procedure for a protein has already been reported and if it keeps part of the required biological activity. Although this can seem redundant, for novel PEGylated proteins, it constitutes a way of knowing if a joint PEGylation-separation process is feasible or if it should focus solely on its purification. If the PEGylation strategy and activity of the protein have been widely studied, the procedure will focus exclusively on purification. On the contrary, PEGylation and purification should be treated at the same time with the aim to achieve effectiveness in both processes, and this last might lead to the use of solid-phase PEGylation. This is recommended especially when the protein possesses in its binding site amino acids susceptible to alteration under a particular
PEGylation chemistry. One alternative for overcoming this is engineered mutations, as long as the knowledge and costs allow it.

Following the line in which a PEGylation tactic has been preset, a second question is how much protein needs to be purified. The response steers to decide between a nonchromatographic or chromatographic technique since nonchromatographic operations are oriented to obtain large amounts of protein at low costs although resolution and purity may be somewhat compromised [65]. However, the decision on what technique should be used is closely related to how abundant and expensive is the ligand and if the ligand is commercially available. So, for costly and/or low-production ligands, AC is a suitable alternative, especially if the recovery of the ligand has not been addressed. Storage, sterilization feasibility, and stability are other factors regarding the ligand that can influence the decision [27]. In this point, other questions related to the ligand must be fulfilled (Figure 4). The first question in ligand selection involves having evidence of the existence of any ligands for the protein. It may be an antibody or even the target of its biological function. When the ligand is very expensive, unknown, scarce, or not isolated, one first trial is the use of pre-existing affinity chromatographic supports. This alternative can be cheap, rapidly developed, powerful, and functional if there is any evidence or suspected affinity interaction between the support and the target molecule. A clear example of this application is the purification of monoPEGylated lysozyme with heparin chromatography which can be regarded as an example of novel applications of existing supports for protein purification [32]. Among the most common affinity supports that can be tried to purify proteins are Heparin Sepharose, Lectin Sepharose, Blue Sepharose, Gelatin Sepharose, Lysine Sepharose, Streptavidin Sepharose, Protein A Sepharose, and IMAC Sepharose. 


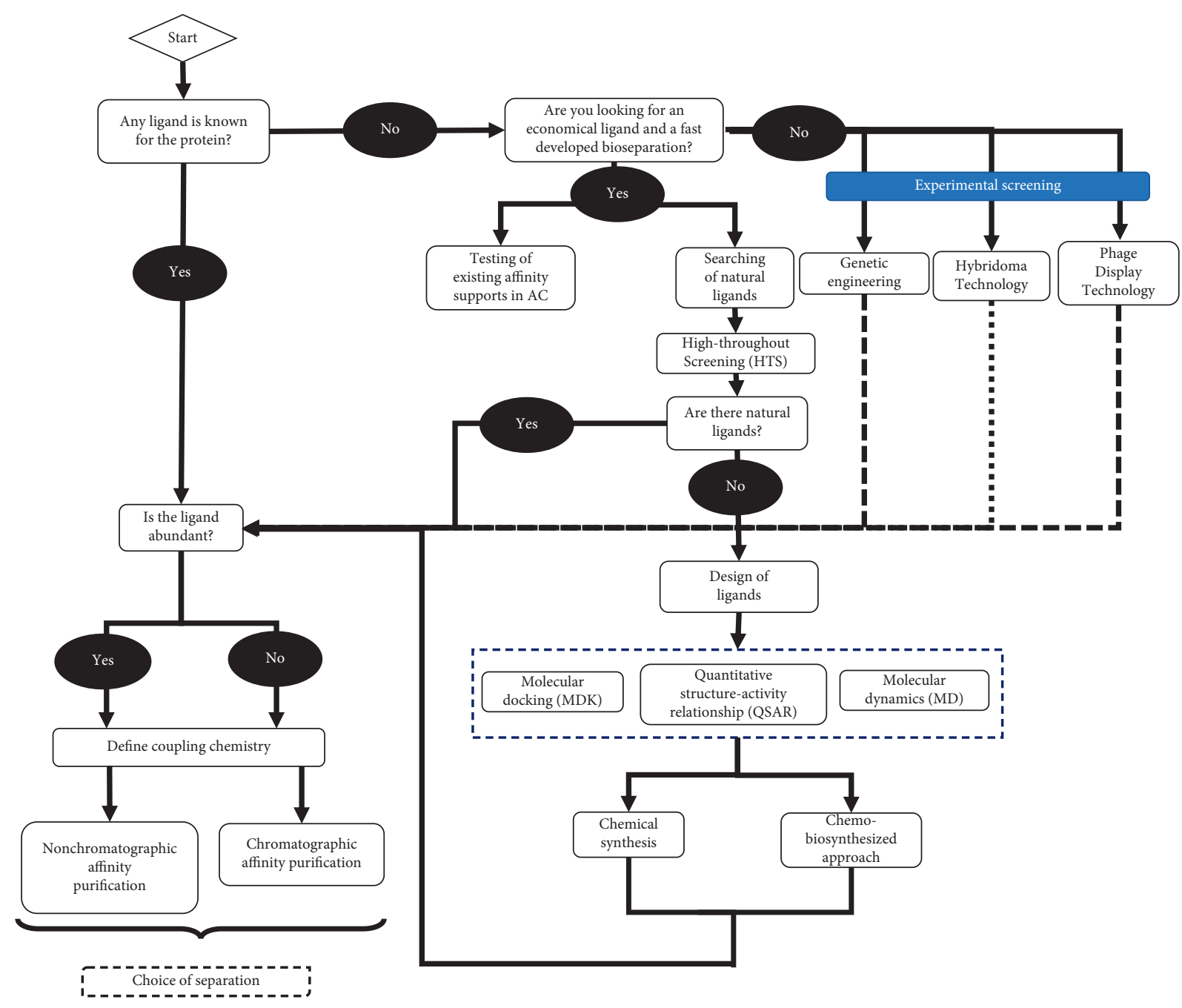

FIgURE 4: Ligand selection for an affinity-based bioseparation for PEGylated proteins.

If no separation in those pre-existing affinity chromatographic supports is detected, the next alternative is to localize a ligand. The identification of a potential ligand can be reached through two main strategies: searching for natural ligands and to design them.

In the first approach, traditional experimental searching involves genetic engineering, antibody production platforms, and high-throughput screening (HTS). On its part, antibody production can be done by exploiting the traditional method of the hybridoma technology, which consists in the creation of a hybrid cell combining a $B$ cell of the spleen of an immunized animal with its antigen and a myeloma cell, with high reproduction of the new cell $[66,67]$. However, one drawback of this option is time consumption. On the contrary, a nontested technology yet is phage display, cloning genes of Fab antibody regions in a vector, which transforms a bacterium using a bacteriophage $[66,68]$. On their part, aptamers, which are oligonucleotides of ribonucleic acid (RNA) or single-strand deoxyribonucleic acid (ssDNA) with three-dimensional structure, also represent viable ligands with high thermal stability and low immunogenicity, capable to be bound with high specificity to proteins [69]. The aptamers have the advantage of being synthetized in great quantities with accuracy at large scale in less time and recognizing a wide spectrum of molecules or biomolecules in comparison with antibodies [69]. In fact, their implementation for the capture of proteins, specifically plasma-derived factors VII, H, and IX, in chromatography has already started [70]. Mutation of ligand gene sequences, alteration of the epitope, or affinity site in antibodies are another options. When the designated ligands are based on mimicking a natural binding, those are called biomimetic affinity ligands [25]; these may be created by chemical, enzymatic, or combined synthesis of their posteriori design and prediction. However, it is essential to have in mind the time investment, cost, and low yields that these synthesis methods may present depending on the nature availability and complexity of these compounds or raw materials.

On the contrary, high-throughput screening techniques (HTST) seem to be a safer and direct choice for screening ligands. This approach, emerged around the end of the 1990's, gained importance in drug discovery inside the pharmaceutical industry [71]. It is based on the assaying of a larger number of candidate compounds $(10,000$ or even 
100,000) against specific targets. [72] Putative compounds are taken from existing libraries of natural molecules or biomolecules. Their benefits include fast testing, low cost, and high-quality data [71]. Some of these characteristics are relative because workstations and automated devices are expensive, and maintenance is mandatory.

As it can be appreciated in Figure 4, when natural ligands are not located and the tridimensional structure and sequence of the protein are known, mimetic ligands may be chemically synthetized, biosynthesized, or chemo-biosynthetized. The design of ligands implies the synthesis of a novel chemical or biochemical ligand (in silico), not previously known. Ligand design can be helped by computational tools as it is described as follows.

Ligand definition can be assisted by computer-aided screening (CAS), computer-aided drug design (CADD), [73] and/or high-throughput screening techniques (HTST). CAS or CADD tests several molecules or biomolecules as possible ligands with tools such as molecular docking (MDK), molecular dynamics (MD), and quantitative structure-activity relationship (QSAR). MDK is a method emerged in the 1980's, which attempts to find interactions between molecules [74] as putative ligands and predicts the binding affinity changing their orientation [75]. The used software for MDK is Auto Dock, Dock, Gold, V Life MDS, and Flex X. On its part, MD simulation is a predictive computational method which allows to understand the structure, folding, conformations, and behavior in biological systems of a specific biomolecule, involving iterative numerical calculations of forces that consider molecules as a set of atoms connected by strings (bounds) governed under classical laws of motion [76]. There are several free and commercial packages used for MD like GROMACS, GROMOS, AMBER, NAMD, CHARMM, COSMOS, and ORAC [77]. MD assists MDK with putative structures of the ligand or target and the estimation of the binding free energies. However, it is also important to mention the limitations when these two modelling tools are considered in ligand design. For example, the need of training and the long time that simulations can take (i.e., weeks or even months in some cases) but setting aside those aspects predicted binding constants are not always accurate since multiple factors (temperature, $\mathrm{pH}$, and environment) can impact the quality of simulations and allosterism can occur in some ligand-target interactions [77]. QSAR has been more widely employed in medical chemistry, and it generates a model that describes the activity as a function of several descriptors of the molecule structure [78]. These descriptors can be constitutional (i.e., molecular weight, atoms number, and bond type), electrostatic, topological (number of bonds, valence electrons, and atom connectivity data), or geometrical [78, 79]. In all these computer-aided tools, experimental execution will be the best way to confirm the obtained results by simulation. Due to the strengths and weaknesses cited for each specific tool in the screening or ligand development, some authors agree to make an integration, for example, an initial CAS or CADD followed by other experimental options like HTS [73]. Reiterative selection processes are suggested too like the case of CAS/CADD-HTS-CAS/ CADD processes. The success of these tools in ligand definition will depend heavily on having the right experience in the field as well as the resources for investment [27]. It should be mentioned that related results might be lengthy and costly as much as experimental searching. As mentioned previously, the synthesis or biosynthesis of these proposed ligands must go hand-inhand with organic chemistry synthesis or biochemical synthesis.

In this same line, after the selection of the ligand (independently of its search or design), and in correlation with the protein abundance and requirements, the choice of the purification operation should be performed. As it has been said, when ligands and proteins are in high amounts, nonchromatographic affinity techniques are recommended. However, there is not yet a guide to select a specific operation between these, so the best option must be selected through experimentation by trial-and-error.

Another consideration is the immobilization method of the ligands when these require to be fixed to a support (i.e., resin, membrane, or particles). At first, the available chemical groups in the affinity ligand must be checked to perform the immobilization as well as to know the chemistry in the support or beads even if these have been previously activated for a particular function and application conditions. The omission of these considerations might result on a decrease in target binding, ligand degradation, or presence of unspecific interactions with contaminants. For PEGylated proteins, hydrophobic, or ionic groups could entail nonspecific interactions. Tentative analysis using docking algorithms can also predict these situations.

Immobilization methods can be classified basically into two branches: covalent and noncovalent methods. The first offers a chemical stable and durable bond between the support and the ligand avoiding leakage of this last during the normal operation. Covalent methods are performed between immobilized ligands with amine groups and supports having $\mathrm{N}$ 'N-carbonyldiimidazole, cyanogen bromide, $\mathrm{N}$-hydroxysuccinimide, or tresyl/tosyl chloride and between sulfhydryl groups with supports having divinylsulfone, epoxy, bromoacetyl, yodoacetyl, maleimide, and tosyl chloride groups [29, 80]. The associated drawbacks of these covalent immobilizations are improper orientation or steric hindrance because these are not site-directed. However, there are also covalent sitedirected attachments, which increase the functionality of the ligands [81]. Inside this group, we can find metalcarrying supports (e.g., iminodiacetic or nitrilotriacetic acids) or attachment via protein bridges. In antibodies, the carbohydrate residues are oxidized with periodate and then bound to hydrazine or amine-activated supports, which might be the most efficient option of those described. However, care must be taken in doing this since overoxidizing promotes denaturing, and oligosaccharide moieties can result damaged in the purified ligands [82]. On their part, noncovalent immobilization tactics rely on a physical and temporal adsorption of the ligand with the 
support, and the ligand can be retained under conditions of elution of the target. Modified avidin/streptavidin, protein $A$ or $G$ supports are used for this purpose. A disadvantage is that a large amount of ligand can be needed due to loss [80].

In brief, the guide proposed here for the operation selection of an affinity-based-strategy for the recovery and/or purification of PEG-modified proteins is founded in the previous knowledge of the protein properties, its PEGylation process, the availability of known ligands, and previously described immobilization methods. Also, multidisciplinary support (computational techniques, genetic engineering, and organic/biochemical synthesis) is suggested, but economic resources, experience, and time are critical factors in the decision about its use and involvement degree.

\section{Conclusion}

The recovery and purification of PEGylated proteins continue to be a challenge, despite the fact that several techniques have been studied and employed. Although affinity loss has been reported in many cases after PEGylation reactions, the change in this property of the modified proteins can be exploited for their purification. In this context, affinity-based strategies are envisioned as the future of the recovery and purification of PEGmodified proteins due to their selectivity and specificity. So far, affinity chromatography has been the unique affinity-based bioseparation tested for PEGylated proteins. Selection and abundance of the ligand and the type of technique will be key points in the successful implementation of affinity separations for PEG-protein conjugates. Until now, only two potential ligands have been identified for PEGylated proteins: anti-PEG antibodies and heparin. Therefore, the search or design of novel ligands is fundamental for the growth of this area. At this point, high-throughput screening and several computeraided tools (i.e., molecular docking, molecular dynamics, and quantitative structure-activity relationship) could be very useful. In the same way, large-scale production of ligands can be promoted through phage display, aptamer production, and genetic engineering along with traditional chemical organic synthesis and biosynthesis. Nonchromatographic affinity techniques like precipitation, aqueous two-phase systems, and membrane and magnetic separations are expected to emerge in this context with integrated operations that will surely improve the yields of the desired PEGylated protein conjugate, saving resources and reducing processing times.

\section{Conflicts of Interest}

The authors declare that they have no conflicts of interest.

\section{Acknowledgments}

This work was supported by the Bioprocess Research Chair (0020209I13) and the FEMSA Biotechnology Center at Tecnologico de Monterrey.

\section{References}

[1] F. M. Veronese and A. Mero, "The impact of PEGylation on biological therapies," BioDrugs, vol. 22, no. 5, pp. 315-329, 2008.

[2] R. W. Payne, B. M. Murphy, and M. C. Manning, "Product development issues for PEGylated proteins," Pharmaceutical Development and Technology, vol. 16, no. 5, pp. 423-440, 2011.

[3] C. Ginn, H. Khalili, R. Lever, and S. Brocchini, "PEGylation and its impact on the design of new protein-based medicines," Future Medicinal Chemistry, vol. 6, no. 16, pp. 1829-1846, 2014.

[4] A. P. Chapman, "PEGylated antibodies and antibody fragments for improved therapy: a review," Advanced Drug Delivery Reviews, vol. 54, no. 4, pp. 531-545, 2002.

[5] X. Zhang, H. Wang, Z. Ma, and B. Wu, "Effects of pharmaceutical PEGylation on drug metabolism and its clinical concerns," Expert Opinion on Drug Metabolism \& Toxicology, vol. 10, no. 12, pp. 1691-1702, 2014.

[6] Allied Market Research, "PEGylated protein therapeutics market by product type (colony stimulating factor, interferon, erythropoietin (EPO), recombinant factor VIII, monoclonal antibody, enzyme, and others) by application (cancer, Autoimmune disease, Hepatitis, Multiple Sclerosis, Hemophilia, Gastrointestinal disorder, and others) by sales channel (hospital pharmacy, online provider, and retail pharmacy)-global opportunity analysis and industry forecast, 2018-2025," 2018.

[7] P. Bailon and W. Berthold, "Polyethylene glycol-conjugated pharmaceutical proteins," Pharmaceutical Science \& Technology Today, vol. 1, no. 8, pp. 352-356, 1998.

[8] M. J. Roberts, M. D. Bentley, and J. M. Harris, "Chemistry for peptide and protein PEGylation," Advanced Drug Delivery Reviews, vol. 64, pp. 116-127, 2012.

[9] G. Pasut and F. M. Veronese, "State of the art in PEGylation: the great versatility achieved after forty years of research," Journal of Controlled Release, vol. 161, no. 2, pp. 461-472, 2012.

[10] A. A. D'souza and R. Shegokar, "Polyethylene glycol (PEG): a versatile polymer for pharmaceutical applications," Expert Opinion in Drug Delivery, vol. 13, no. 9, pp. 461-472, 2016.

[11] F. M. Veronese and G. Pasut, "PEGylation, successful approach to drug delivery," Drug Discovery Today, vol. 10, no. 21, pp. 1451-1458, 2008.

[12] K. Mayolo-Deloisa, J. González-Valdez, D. Guajardo-Flores, O. Aguilar, J. Benavides, and M. Rito-Palomares, "Current advances in the non-chromatographic fractionation and characterization of PEGylated proteins," Journal of Chemical Technology \& Biotechnology, vol. 86, no. 1, pp. 18-25, 2011.

[13] J. R. Molek and A. L. Zydney, "Ultrafiltration characteristics of pegylated proteins," Biotechnology and Bioengineering, vol. 95, no. 3, pp. 474-482, 2006.

[14] C. Delgado, F. Malik, B. Selisko, D. Fischer, and G. E. Francis, "Quantitative analysis of polyethylene glycol (PEG) in PEGmodified proteins/cytokines by aqueous two-phase systems," Journal of Biochemical and Biophysical Methods, vol. 29, no. 34, pp. 237-250, 1994.

[15] J. González-Valdez, J. L. F. Cueto, and M. Rito-Palomares, "Potential application of aqueous two-phase systems for the fractionation of RNase A and $\alpha$-Lactalbumin from their PEGylated conjugates," Journal of Chemical Technology \& Biotechnology, vol. 86, no. 1, pp. 26-33, 2011.

[16] M. Cisneros-Ruiz, K. Mayolo-Deloisa, M. Rito-Palomares, and T. M. Przybycien, "Separation of PEGylated variants of ribonuclease $\mathrm{A}$ and apo- $\alpha$-lactalbumin via reversed phase 
chromatography," Journal of Chromatography A, vol. 1360, pp. 309-316, 2014.

[17] S. Jevševar, M. Kunstelj, and V. G. Porekar, "PEGylation of therapeutic proteins," Biotechnology Journal: Healthcare Nutrition Technology, vol. 5, no. 1, pp. 113-128, 2010.

[18] S. Yamamoto, S. Fujii, N. Yoshimoto, and P. Akbarzadehlaleh, "Effects of protein conformational changes on separation performance in electrostatic interaction chromatography: unfolded proteins and PEGylated proteins," Journal of Biotechnology, vol. 132, no. 2, pp. 196-201, 2007.

[19] N. Yoshimoto and S. Yamamoto, "PEGylated protein separations: challenges and opportunities," Biotechnology Journal, vol. 7, no. 5, pp. 592-593, 2012.

[20] D. Pfister and M. Morbidelli, "Process for protein PEGylation," Journal of Controlled Release, vol. 180, pp. 134-149, 2014.

[21] J. M. Harris and R. B. Chess, "Effect of pegylation on pharmaceuticals," Nature Reviews Drug Discovery, vol. 2, no. 3, pp. 214-221, 2003.

[22] F. M. Veronese, P. Caliceti, O. Schiavon, and L. Sartore, "Preparation and properties of monomethoxypoly (ethylene glycol)-modified enzymes for therapeutic applications," in Poly (Ethylene Glycol) Chemistry, H. Milton H, Ed., Springer, New York, NY, USA, pp. 127-137, 1992.

[23] K. Park, "Ligand affinity: multivalency counterbalances PEGylation," Journal of Controlled Release, vol. 194, p. 351, 2014.

[24] N. Labrou and Y. D. Clonis, "The affinity technology in downstream processing," Journal of Biotechnology, vol. 36, no. 2, pp. 95-119, 1994.

[25] K. Mondal and M. N. Gupta, "The affinity concept in bioseparation: evolving paradigms and expanding range of applications," Biomolecular Engineering, vol. 23, no. 2-3, pp. 59-76, 2006.

[26] A. T. Hanke and M. Ottens, "Purifying biopharmaceuticals: knowledge-based chromatographic process development," Trends in Biotechnology, vol. 32, no. 4, pp. 210-220, 2014.

[27] M. Urh, D. Simpson, and K. Zhao, "Affinity chromatography: general methods," in Methods in Enzymology 463 Guide to protein purification, R. R. Burgess and M. P. Deutscher, Eds., vol. 463, pp. 417-438, Elsevier, Alpharetta, GA, USA, 2009.

[28] G. Fassina, "Affinity Chromatography," in Encyclopedia of Life Sciences, pp. 1-3, Nature Publishing Group, London, UK, 2001.

[29] D. S. Hage and P. F. Ruhn, "An introduction to affinity chromatography," in Handbook of Affinity Chromatography, D. S. Hage and J. Cazes, Eds., vol. 39, pp. 2-13, Taylor \& Francis CRC Press, Boca Raton, FL, USA, 2005.

[30] G. Fassina, M. Ruvo, G. Palombo, A. Verdoliva, and M. Marino, "Novel ligands for the affinity-chromatographic purification of antibodies," Journal of Biochemistry and Biophysical Methods, vol. 49, no. 1-3, pp. 481-490, 2001.

[31] J. Fitzgerald, P. Leonard, E. Darcy, and R. O'Kennedy, "Immunoaffinity chromatography," in Protein Chromatography: Methods and Protocols, D. Walls and S. T. Loughran, Eds., pp. 35-59, Humana Press, Totowa, NJ, USA, 2011.

[32] L. A. Mejía-Manzano, M. E. Lienqueo, E. J. EscalanteVázquez, M. Rito-Palomares, and J. A. Asenjo, "Optimized purification of mono-PEGylated lysozyme by heparin affinity chromatography using response surface methodology," Journal of Chemical Technology and Biotechnology, vol. 92, no. 10, pp. 2554-2562, 2017.

[33] L. A. Mejía-Manzano, G. Sandoval, M. E. Lienqueo, P. Moisset, M. Rito-Palomares, and J. A. Asenjo, "Simulation of mono-PEGylated lysozyme separation in heparin affinity chromatography using a general rate model," Journal of Chemical Technology and Biotechnology, vol. 93, no. 7, pp. 1980-1987, 2017.

[34] Z. Wen and B. Niemeyer, "Preparation and characterization of PEGyated concanavalin a for affinity chromatography with improved stability," Journal of Chromatography B, vol. 879, no. 20, pp. 1732-1740, 2011.

[35] J. González-Valdez, A. Yoshikawa, J. Weinberg, J. Benavides, M. Rito-Palomares, and T. M. Przybicien, "Toward improving selectivity in affinity chromatography with PEGylated affinity ligands: the performance of PEGylated protein A," Biotechnology Progress, vol. 30, no. 6, pp. 1364-1379, 2014.

[36] R. P. Garay and J. P. Labaune, "Immunogenicity of polyethylene glycol (PEG)," The Open Conference Proceedings Journal, vol. 2, no. 1, pp. 104-107, 2011.

[37] H. Schellekens, W. E. Hennink, and V. Brinks, "The immunogenicity of polyethylene glycol: facts and fiction," Pharmaceutical Research, vol. 30, no. 7, pp. 1729-1734, 2013.

[38] M. G. P. Saifer, L. D. Williams, M. A. Sobczyk, S. J. Michaels, and M. R. Sherman, "Selectivity of binding of PEGs and PEGlike oligomers to anti-PEG antibodies induced by methoxyPEG-proteins," Molecular Immunology, vol. 57, no. 2, pp. 236-246, 2014.

[39] P. Zhang, F. Sun, S. Liu, and S. Jiang, "Anti-PEG antibodies in the clinic: current issues and beyond PEGylation," Journal of Controlled Release, vol. 244, pp. 184-193, 2016.

[40] Y. Xu, J. T. Mehl, R. Bakhtiar, and E. J. Woolf, "Immunoaffinity purification using anti-PEG antibody followed by two-dimensional liquid chromatography/tandem mass spectrometry for the quantification of a PEGylated therapeutic peptide in human plasma," Analytical Chemistry, vol. 82, no. 16, pp. 6877-6886, 2010.

[41] C. J. Fee and J. M. Van Alstine, "PEG-proteins: reaction engineering and separation issues," Chemical Engineering Science, vol. 61, no. 3, pp. 924-939, 2006.

[42] J. Wang, Y. Wang, T. Hu et al., "An oriented adsorption strategy for efficient solid phase PEGylation of recombinant staphylokinase by immobilized metal-ion affinity chromatography," Process Biochemistry, vol. 47, no. 1, pp. 106-112, 2012.

[43] E. T. Baran, N. Özer, and V. Hasirci, "Solid-phase enzyme modification via affinity chromatography," Journal of Chromatography B, vol. 794, no. 2, pp. 311-322, 2003.

[44] Z. Huang, C. Ye, Z. Liu et al., "Solid-phase N-terminus PEGylation of recombinant human fibroblast growth factor 2 on heparin-sepharose column," Bioconjugate Chemistry, vol. 23, no. 4, pp. 740-750, 2012.

[45] Z. Huang, G. Zhu, C. Sun et al., "A novel solid-phase sitespecific PEGylation enhances the in vitro and in vivo biostability of recombinant human keratinocyte growth factor 1," PloS One, vol. 7, no. 5, Article ID e36423, 2012.

[46] X. Suo, C. Zheng, P. Yu, X. Lu, G. Ma, and Z. Su, "Solid phase pegylation of hemoglobin," Artificial Cells, Blood Substitutes, and Biotechnology, vol. 37, no. 4, pp. 147-155, 2009.

[47] B. K. Lee, J. S. Kwon, H. J. Kim, S. Yamamoto, and E. K. Lee, "Solid-phase PEGylation of recombinant interferon $\alpha$-2a for site-specific modification: process performance, characterization, andin VitroBioactivity," Bioconjugate Chemistry, vol. 18, no. 6, pp. 1728-1734, 2007.

[48] S. Raja, V. R. Murty, V. Thivaharan, V. Rajasekar, and V. Ramesh, "Aqueous two phase systems for the recovery of biomolecules-a review," Science Technology, vol. 1, no. 1, pp. 7-16, 2011. 
[49] A. M. Goja, H. Yang, M. Cui, and C. Li, "Aqueous two-phase extraction advances for bioseparation," Journal of Bioprocess Biotechnology, vol. 4, no. 1, pp. 1-8, 2019.

[50] A. L. Grilo, M. Raquel Aires-Barros, and A. M. Azevedo, "Partitioning in aqueous two-phase systems: fundamentals, applications and trends," Separation \& Purification Reviews, vol. 45, no. 1, pp. 68-80, 2016.

[51] L. J. Karr, S. G. Shafer, J. M. Harris, J. M. Van Alstine, and R. S. Snyder, "Immuno-affinity partition of cells in aqueous polymer two-phase systems," Journal of Chromatography A, vol. 354, pp. 269-282, 1986.

[52] F. Ruiz-Ruiz, J. Benavides, O. Aguilar, and M. Rito-Palomares, "Aqueous two-phase affinity partitioning systems: current applications and trends," Journal of Chromatography A, vol. 1244, pp. 1-13, 2012.

[53] J. González-Valdez, M. Rito-Palomares, and J. Benavides, "Effects of chemical modifications in the partition behavior of proteins in aqueous two-phase systems: a case study with RNase A," Biotechnology Progress, vol. 29, no. 2, pp. 378-385, 2013.

[54] A. M. Azevedo, P. A. J. Rosa, I. F. Ferreira, and M. R. AiresBarros, "Chromatography-free recovery of biopharmaceuticals through aqueous two-phase processing," Trends in Biotechnology, vol. 27, no. 4, pp. 240-247, 2009.

[55] P. A. J. Rosa, A. M. Azevedo, I. F. Ferreira et al., "Affinity partitioning of human antibodies in aqueous two-phase systems," Journal of Chromatography A, vol. 1162, no. 1, pp. 103-113, 2007.

[56] R. Hatti-Kaul and B. Mattiason, Transgenic Plants: A Production System for Industrial and Pharmaceutical Proteins, M. Owen and J. Pen, Eds., John Wiley \& Sons, England, UK, 1996.

[57] H. Zou, Q. Luo, and D. Zhou, "Affinity membrane chromatography for the analysis and purification of proteins," Journal of Biochemical and Biophysical Methods, vol. 49, no. 13, pp. 199-240, 2001.

[58] F. Hilbrig and R. Freitag, "Protein purification by affinity precipitation," Journal of Chromatography B, vol. 790, no. 1-2, pp. 79-90, 2003.

[59] F. Hilbrig, G. Stocker, J.-M. Schläppi, H. Kocher, and R. Freitag, "Utilization of group specific ligands in the downstream processing of proteins by affinity precipitation," Food and Bioproducts Processing, vol. 84, no. 1, pp. 28-36, 2006.

[60] I. Safarik and M. Safarikova, "Magnetic techniques for the isolation and purification of proteins and peptides," Biomagnetic Research and Technology, vol. 2, no. 7, pp. 1-17, 2004.

[61] L. Borlido, A. M. Azevedo, A. C. A. Roque, and M. R. AiresBarros, "Magnetic separations in biotechnology," Biotechnology Advances, vol. 31, no. 8, pp. 1374-1385, 2013.

[62] R. Hennig, K. Pollinger, J. Tessmar, and A. Goepferich, "Multivalent targeting of AT1 receptors with angiotensin IIfunctionalized nanoparticles," Journal of Drug Targeting, vol. 23, no. 7-8, pp. 681-689, 2015.

[63] R. N. D’Souza, A. M. Azevedo, M. R. Aires Barros et al., "Emerging technologies for the integration and intensification of downstream bioprocesses," Pharmaceutical Bioprocessing, vol. 1, no. 5, pp. 423-440, 2013.

[64] J. S. Becker, O. R. T. Thomas, and M. Franzreb, "Protein separation with magnetic adsorbents in micellar aqueous twophase systems," Separation and Purification Technology, vol. 65 , no. 1 , pp. 46-53, 2009.

[65] M. N. Gupta, "Purification of natural occurring biomaterials," in Natural-Based Polymers for Biomedical Applications,
R. L. Reis, N. Neves, J. F. Mano, M. E. Gomes, A. P. Marques, and H. S. Azevedo, Eds., Woodhead Publishing in Materials, Cambridge, England, 2008.

[66] L. S. Carvalho, O. B. da Silva, G. C. de Almeida, J. D. de Oliveira, N. S. Parachin, and T. S. Carmo, "Production Processes for Monoclonal Antibodies," in Fermentation Processes, A. Faustino Jozala, Ed., InTechOpen, Rijeka, Coratia, 2017.

[67] C. Zhang, Antibody Methods and Protocols, G. Proetzel and H. Ebersbach, Eds., pp. 117-135, Humana Press, Totowa, NJ, USA, 2012.

[68] G. L. Verdine, T. N. Grossmann, R. E. Moellering, T. H. J. Yeh, Y. R. Y. Liang, and Y. Oak, "Bifunctional stapled polypeptides and uses thereof," U.S. Patent and Trademark Office, Washington, DC, USA, U.S. Patent No. 9,163,330, 2015.

[69] K.-M. Song, S. Lee, and C. Ban, "Aptamers and their biological applications," Sensors, vol. 12, no. 1, pp. 612-631, 2012.

[70] C. Forier, E. Boschetti, M. Ouhammouch et al., "DNA aptamer affinity ligands for highly selective purification of human plasma-related proteins from multiple sources," Journal Of Chromatography A, vol. 1489, pp. 39-50, 2017.

[71] R. Macarron, M. N. Banks, D. Bojanic et al., "Impact of highthroughput screening in biomedical research," Natural Review Drug Discovery, vol. 10, pp. 188-195, 2011.

[72] P. Szymański, M. Markowicz, and E. Mikiciuk-Olasik, “Adaptation of high-throughput screening in drug discovery-toxicological screening tests," International Journal of Molecular Science, vol. 13, no. 1, pp. 427-452, 2011.

[73] S. J. Y. Macalino, V. Gosu, S. Hong, and S. Choi, "Role of computer-aided drug design in modern drug discovery," Archives of Pharmacal Research, vol. 38, no. 9, pp. 1686-1701, 2015.

[74] Y. Z. Chen and D. G. Zhi, "Ligand-protein inverse docking and its potential use in the computer search of protein targets of a small molecule," Proteins: Structure, Function, and Genetics, vol. 43, no. 2, pp. 217-226, 2001.

[75] B. Mukesh and K. Rakesh, "Molecular docking: a review," International Journal of Ayurveda Research, vol. 2, no. 6, pp. 1746-1751, 2011.

[76] S. A. Adcock and J. A. McCammon, "Molecular dynamics: survey of methods for simulating the activity of proteins," Chemical Reviews, vol. 106, no. 5, pp. 1589-1615, 2006.

[77] D. Vlachakis, E. Bencurova, N. Papangelopoulos, and S. Kossida, "Current state-of-the-art molecular dynamics methods and applications," Advances in Protein Chemistry and Structural Biology, vol. 94, pp. 269-313, 2014.

[78] A. Dudek, T. Arodz, and J. Galvez, "Computational methods in developing quantitative structure-activity relationships (QSAR): a review," Combinatorial Chemistry \& High Throughput Screening, vol. 9, no. 3, pp. 213-228, 2006.

[79] A. Cherkasov, E. N. Muratov, D. Fourches et al., "QSAR modeling: where have you been? Where are you going to?" Journal of Medicinal Chemistry, vol. 57, no. 12, pp. 4977-5010, 2014.

[80] A. C. Moser and D. S. Hage, "Immunoaffinity chromatography: an introduction to applications and recent developments," Bioanalysis, vol. 2, no. 4, pp. 769-790, 2010.

[81] M. Nisnevitch and M. A. Firer, "The solid phase in affinity chromatography: strategies for antibody attachment," Journal of Biochemical and Biophysical Methods, vol. 49, no. 1-3, pp. 467-480, 2001.

[82] A. Makaraviciute and A. Ramanaviciene, "Site-directed antibody immobilization techniques for immunosensors," Biosensors and Bioelectronics, vol. 50, pp. 460-471, 2013. 